\title{
Cuatro notas inéditas sobre el clasicismo de Garcilaso en sus sonetos
}

\author{
Bienvenido Morros \\ Universitat Autònoma de Barcelona \\ bienvenido.morros@uab.cat \\ Fecha de recepción: 03/05/2010, Fecha de publicación: 20/05/2010 \\ <URL: http://www.studiaaurea.com/articulo.php?id=130>
}

\section{Resumen}

El autor vuelve sobre los sonetos X, XII, VII, y la canción V, para reinterpretarlas a la luz de varias fuentes clásicas todavía no consideradas.

\section{Palabras clave}

poesía del siglo XVI, cancionero petrarquista, sonetos y canciones, Garcilaso.

\begin{abstract}
Four Unpublished Notes on Classicism in Garcilaso's Sonnets

The author offers readings of Sonnets X, XII and VII, and of Canción V, reinterpreting them in the light of a number of Classical sources that have not previously been taken into account.

Key words

Sixtenth-Century Poetry, Petrarchan Canzoniere, sonnets and songs, Garcilaso.
\end{abstract}


Garcilaso no solo imitó en sus sonetos a los poetas de cancionero, a Petrarca o a Ausiàs March, sino también a los clásicos. En las páginas que siguen veremos dos casos de esa imitación, en la que el toledano la lleva a cabo de modo sutil. De hecho, de haber desconocido los textos en los que se basa difícilmente habríamos entendido cabalmente los dos sonetos que nos disponemos a comentar.

El soneto X de Garcilaso es de los más controvertidos, porque una parte de la crítica lo ha considerado compuesto a raíz de la muerte de su dama, mientras otra lo ha creído escrito con motivo del hallazgo de unas prendas que lo retrotraen a un período de felicidad perdida.

Los partidarios de la primera interpretación lo han supuesto dirigido a Isabel Freyre y lo han puesto en relación con un pasaje de la égloga en que Nemoroso saca de una bolsa el mechón de los cabellos de su dama fallecida y, derramando lágrimas sobre cada uno de ellos, lo cuenta uno a uno para acto seguido devolverlos a la bolsa en que los tiene atados. Después de haber llevado a cabo esta acción siente un gran alivio.

Para el soneto X Garcilaso ha tenido en cuenta un pasaje de la Eneida en que la reina Dido decide poner fin a su vida arrojándose a una hoguera que ha preparado con la ropa de Eneas. Ha intentado retenerlo por todos los medios, pero no ha podido hacerlo, porque el troyano ha sido reclamado por los dioses para llevar a cabo la difícil empresa de crear una nueva civilización, la del imperio romano. Es esa una misión a la que Eneas no puede ni debe renunciar, a pesar del amor que pueda llegar a sentir por la reina de Cártago.

Garcilaso ha reproducido el mismo lamento que Dido ante las prendas de Eneas. Si las invocaba diciendo «Oh dulces prendas por mi mal halladas,/ dulces y alegres cuando Dios quería?», otro tanto había hecho su modelo al hacerle exclamar a su personaje Dulces exuviae, dum fata deusque sinebat». En el caso de Garcilaso parece que las prendas se las encuentra por casualidad, y es en ese instante en que le viene a la memoria el tiempo que lo acompañaron en la felicidad.

Hay un detalle en el soneto de Garcilaso que no entenderíamos de no conocer la fuente en la que se inspira. En el primer cuarteto afirma que las prendas y su memoria se han conjurado para provocarle la muerte. En el primer terceto las hace responsables del bien que le proporcionaron en el pasado, y es por eso que desea que le prive del mal que siente en la actualidad provocándole la muerte. ¿Cómo unas prendas pueden causar la muerte física del poeta? La respuesta está en el pasaje de la Eneida que ha decidido imitar: Dido se suicida con las prendas de su ser querido, y son ellas, junto a la espada, que también es una prenda de Eneas, las que le producen la muerte: primera se clava la espada y después, como ya hemos dicho, se introduce en la pira en que arden las ropas de su ser querido.

En Garcilaso la representación inesperada de las prendas le provocan un dolor que no llega a paliar en ningún momento, mientras que Nemoroso, en la égloga I, la visión de esas prendas le producen alivio. Por eso la situación del poeta es muy distinta en los dos casos. Como Garcilaso, elige las prendas para que ejecuten su muerte (al igual que hace Dido), pero como Nemoroso las guarda para paliar el 
dolor y no desear la muerte en esos momentos en los que cuenta los cabellos de Elisa uno a uno. En un caso agrava el dolor, mientras que el otro lo distrae de ese dolor.

Si el soneto lo interpretamos como he propuesto arriba, difícilmente Garcilaso podía dedicárselo a Elisa, esto es, a Isabel Freyre, porque alude a un período de felicidad que nunca tuvo con la dama portuguesa. Sólo podía darse el caso de habérselo dedicado a ella si Garcilaso, al servirla, hubiera obtenido algún tipo de prenda, no necesariamente los cabellos que tan celosamente guarda Nemoroso en su paño de color blanco. Podría haber identificado los bienes que recibe de su dama con un gesto de generosidad en el que no se Isabel no se prodigó demasiado, al menos para con el poeta que la hizo famosa a través de sus versos. Por eso no descartaría, sin llegar a poner la mano en el fuego para no quemarme, que el soneto se lo dedicase a la dama napolitana, por la que fue correspondido durante algún tiempo y luego traicionado por entregarse la dama a otro caballero, seguramente el Emperador, a quien nuestro poeta no tenía demasiada simpatía, como pone de manifiesto en la canción III.

En el soneto XII, Garcilaso se siente objeto de un deseo que parece incapaz de refrenar y experimenta un mal del que cree que no va a curarse. Ese deseo que se le desboca le trae a la memoria las pinturas de dos personajes mitológicos que acometieron empresas muy superiores a sus posibilidades. Los personajes en cuestión son Ícaro y Faetón, quienes por diversos motivos quisieron volar cuando carecían de las aptitudes y capacidades para hacerlo. Los dos cayeron al mar, y uno de ellos fulminado por un rayo de Júpiter, que quería evitar a toda costa los estragos que estaba produciendo Faetón llevando el carro de su padre.

A Garcilaso este soneto se lo inspiró una oda en que Horacio invita a una antigua amante, Filis, a su casa para celebrar el cumpleaños de Mecenas. Después de hablarle de los preparativos de la fiesta le menciona al joven Télefo, del que Filis se ha enamorado. Pero se lo desaconseja por ser un muchacho de clase social muy superior a la suya y por tener ya una joven atractiva con la que sale. Es entonces cuando mencionado los casos de Faetón y de Belerofonte para que con su ejemplo aprenda a querer lo apropiado y desechar lo que es dispar. Vale la pena leer el pasaje en que Horacio reprocha a su examante haberse fijado en un joven con el que no tiene ninguna posibilidad.

Telephum, quem tu petis, occupavit

Non tuae sortis iuvenem puella

Dives et lasciva tenetque grata

Compede vinctum.

Terret ambustus Phaethon avaras

Spes, et exemplum grave praebet ales

Pegasus terrenum equitem gravatus

Bellerophontem,

Simper ut te digna sequare et ultra

Quam licet sperare nefas putando

Disparem vites [...] (IV, 11). 
La única diferencia con el soneto de Garcilaso es el cambio de Ícaro por el de Belerofonte, quien, confiando en las fuerzas de su caballo alado Pegaso, quiso llegar hasta el Olimpo, pero Júpiter se lo impidió clavando un aguijón en el corcel que lo enloqueció hasta el punto de que su jinete no pudo controlarlo y se precipitó al vacío. El de Belerofonte es un caso parecido al de Ícaro y Faetón, y Garcilaso para desmarcarse de su modelo introdujo el cambio del uno por el otro.

Es por esta oda que he llegado a la conclusión de que la dama napolitana, porque el soneto lo creo dedicado a ella, había de ser una dama de la más alta aristocracia. A través de otros indicios, empezando por el nombre, que reproduce en el soneto XIX, conjeturé que la dama en cuestión era la esposa del príncipe de Salerno, Isabella Villamarina a cuya casa Garcilaso debió asistir muchas veces, porque en ella la princesa celebraba reuniones de carácter literario.

Otro poeta, amigo de Garcilaso, Luigi Tansillo también compuso varios poemas en los que hacía intervenir a Faetón e Ícaro con el mismo fin que Horacio y Garcilaso de la Vega. Luigi Tansillo se siente impulsado por un deseo similar al del hijo de Dédalo que le lleva a volar muy alto (en sus aspiraciones amorosas) sin temer la caída, porque piensa que, en esa empresa, puede perder la vida pero no el deseo: «Tem'io, qualor giú guardo, il vol tropp’alto,/ ond'e ei mi grida e mi promette altero,/ ché, s'al superbo vol cayendo, io pero,/ l'onor fia eterno, se mortal è il salto./ Ché s' altri [como Ícaro], cui disio simil compunse,/ dié nome eterno al mar col suo morire,/ ove l'ardite penne il sol disgiunse,/ ancor di me le genti potran dire:/ -Quest'aspirò a le stelle, e s'ei non giunse,/ la vita venne men, man non l'ardire!» (Canzoniere, I, ii, 5-14). En un madrigal, el mismo poeta napolitano empieza equiparándose con una mariposa que se quema al acercarse a la luz (a él le ocurre otro tanto al aproximarse a los ojos y cabellos de su amada) y sigue comparándose con Ícaro y Faetón a la vez, porque aspira también a conseguir una muerte tan digna como la de ellos, para acabar apelando a su propio deseo que no parece satisfecho con el trágico pero gozoso final de la mariposa: «S’ un Icaro, un Fetonte,/ per troppo ardir già spenti il mondo esclama:/ quel che perder di vita, elli gan di fama./ Di me, farfalla pargoletta e frale... e col volo cercai morte sí digna?... Ah, superbo, sfrenato, alto desio,/ che chiedi? Ancor piú voi? » (II, xii, 33-36, 41 y 52-53). En el soneto citado en primer lugar incluye epígrafe que ilustra ese uso que los tres poetas hacen de loa mitos en cuestión: «Aspirò ad un amore tant'alto, che, anche cayendo, egli sarà lodato per la sua adacia». Y es que el poeta napolitano se había enamorado nada menos que de María de Aragón, la esposa del marqués del Vasto, y de Laura Monforte, dama también perteneciente a la alta aristocracia.

La única oda que compuso Garcilaso ha sido ya estudiada desde todos los puntos de vista posibles. Nada hay que pueda decirse de las fuentes que el toledano llegó a usar. Nuestro poeta compone la oda para reprochar a doña Violante Sanaeverino el poco caso que hace a su pretendiente, Mario Galeota, que está inmerso en una gran depresión por el desdén con que es tratado por su dama. Para definir la naturaleza del amor que siente hacía doña Violante lo describe amarrado a la concha de Venus, en la que está esclavizado por entregarse al castigo que lleva 
su nombre, el del galeote que rema en los barcos de la armada española. No hace falta insistir en la simbología de la concha de la que deja constancia Fulgencio en su libro sobre mitología.

Garcilaso llama a la desdeñosa Violante la flor de Gnido, no sólo porque la dama vivía en un barrio de su ciudad con un nombre muy parecido (Nido), sino especialmente porque conocía la historia que desde muy antiguo circulaba sobre la Venus de ese templo. La historia es la de un muchacho que se enamoró de la estatua, por la que se volvió loco de amor. Garcilaso ha decidido identificar a su interlocutora con una estatua de Venus que había enamorado a un joven noble que, ocultándose en el templo en que la diosa de mármol se exhibía, dejó en ella las manchas de su profanación para después arrojarse al mar y desaparecer para siempre. La flor del Gnido es esa estatua que esculpió Praxíteles y que se convirtió en el tesoro más preciado de la ciudad que la adquirió. Doña Violante también parece estar hecha del mismo mármol que la Venus del Nido.

La historia sobre el joven que se enamoró de la estatua de Venus en Gnido la cuenta ya con cierto detalle Luciano en sus Amores: «11-17: «Como habíamos decidido fondear en Cnido para contemplar también el templo de Afrodita (famoso por tener la obra más atractiva de la pericia de Praxíteles), arribamos a tierra suavemente, me imagino que con la propia diosa como guía de nuestra nave [...] En medio de él está erigida la diosa —obra de arte bellísima de mármol de Paros— sonriendo ligeramente con una parte de su boca abierta. Toda su belleza sin cubrir por ningún ropaje se muestra desnuda, excepto que directamente emplea una de sus manos para tratar de cubrirse el pubis [...] Y cuando ya estábamos cansados de admirarla, advertimos una señal en uno de sus muslos, como una mancha en un vestido [...] la diaconisa que estaba a nuestro lado nos contó una historia extrańa e increíble. Nos dijo que un joven procedente de una familia bastante distinguida (cuya acción hizo que se silenciara su nombre), que visitaba con frecuencia el templo, se enamoró de la diosa por funesto azar. Se pasaba el día entero en el recinto y al principio daba la impresión de una veneración fanática: nada más levantarse por la mañana, desde la cama y antes de que amaneciera se dirigía al templo y por la tarde, después de ponerse el sol, volvía a su casa a regañadientes. Todo el día está sentado frente a la diosa, con los ojos fijos en ella sin interrupción, entre secretos cuchicheos y lamentaciones amorosas en una conversación furtiva [...] No obstante, cuando ya su enfermedad se fue agudizando más, todo el muro se iba llenando de escritos y las cortezas de todos los árboles blandos proclamaban el nombre de Afrodita [...] Al final, las tensiones violentas de su pasión se convirtieron en desesperación y descubrió la audacia como alcahueta de su lujuria. En efecto, un día, cuando ya se había puesto el sol, se deslizó en silencio sin que los vieran los presentes detrás de la puerta y se ocultó en el interior del templo, sin moverse y casi sin respirar, de modo que cuando los guardianes del templo cerraron desde fuera la puerta, el nuevo Anquises quedó encerrado dentro [...] Esas huellas de los abrazos amorosos se advirtieron cuando llegó el día, y la diosa tiene esa mancha como comprobación de lo que sufrió. En lo que se refiere al joven se dice, de acuerdo con el relato popu- 
lar, que se arrojó contra las rocas o contra las olas del mar y desapareció por completo» (Luciano 1990: 124-129). Luciano la recuerda mucho más brevemente en Retratos, 4: «¿Oíste la historia que sobre ella cuentan los lugareños, de que alguien, enamorado de la estatua, sin que nadie se diera cuenta, se acostó con ella en el templo en la medida que se puede estar con una estatua?» (430). Entre los autores romanos, la recuerdan Plinio el viejo y Valerio Máximo: «Praxiteles marmore nobilitatus est Gnidiaque Venere praecipue, vesano amore cuiusdam iuvenis insigni» (Historia natural, VII, xxxviii, 126), "Praxitelis aetatem inter statuarios diximus, qui marmoria gloria superavit etiam semet. opera eius sunt Athenis in Ceramico, sed ante omnia est non solum Praxitelis, verum in toto orbe terrarum Venus, quam ut viderent, multi navigaverunt Cnidum. duas fecerat simulque vendebat, alteram velata specie, quam ob id praetulerunt quorum condicio erat, Coi, cum eodem pretio detulisset, severum id ac pudicum arbitrantes; reiectam Cnidii emerunt, inmensa differentia famae. Voluit eam a Cnidiis postea mercari rex Nicomedes, totum aes alienum, quod erat ingens, civitatis dissoluturum se promittens. omnia perpeti maluere, nec inmerito; illo enim signo Praxiteles nobilitavit Cnidum. aedicula eius tot aperitur, ut conspici possit undique effigies deae, favente ipsa, ut creditur, facta. nec minor ex quacumque parte admiratio est. ferunt amore captum quendam, cum delituisset noctu, simulacro cohaesisse, eiusque cupiditatis esse indicem maculam.» (Historia natural, XXXVI, iv, 21), "Cuius coniugem Praxiteles in marmore quasi spirantem in templo Cnidiorum collocauit, propter pulchritudinem operis a libidinoso cuiusdam conplexu parum tutam [...] quid enim vacua rationis animalia arte decepta miremur, cum hominis sacrilegam cupiditatem muti lapidis liniamentis excitatam videamus?» (Facta et dicta memorabilia, VIII, 11, 1). La siguieron contando los autores de la tardía antigüedad tanto en griego como en latín:»Había un individuo que parecía estar enamorado de la estatua de Afrodita que se alza, desnuda, en Gnido; le consagraba ofrendas y aseguraba que le consagraría más, con el propósito de desposarla» (Filóstrato, Vida de Apolonio, VI, 40; en 1979: 392), «Había otra Afrodita de mármol en Cnido, era también bella; otro hombre se enamoró de ésta y se unió a la piedra. [...] ¡Tanto pudo engañar el arte que llegó a ser el seductor de los hombres pasionales hacia el abismo! [...] Pues ningún hombre sensato se unió a una diosa..., ni se enamoró de... una piedra. En cambio, a vosotros os engaña el arte con otro encantamiento, conduciéndoos, aunque no sea a enamoraros, sí a honrar y a adorar las estatuas...» (Clemente de Alejandría, Protréptico, en 1994: 119-120), «De la misma manera... un joven de no innoble linaje..., arrastrado por los amores de Venus, debido a la cual Gnido tiene renombre, también trataba relaciones amatorias con la estatua de la misma deidad, utilizando el lecho nupcial con el fin de alcanzar los placeres consiguientes» (Arnobio, Adversus naciones, VI, 22), «Dirás, si en la pétrea Cnido contemplas a Cipris, que a las piedras mismas, siendo piedra, inflama; y del dulce Deseo tespiada, que no ya a la roca, sino al frío diamante fuego llevar sabría. Tales dioses Praxíteles puso en distintas regiones para que no se abrase todo en la doble hoguera» (Antípatro, en Antología palatina, XVI, 167, en 1978: 339). En el Renacimiento, la mencio- 
nan muy brevemente tanto Benedetto Varchi, Due lezioni (Florencia, 1549, p. 104), como Antón Francesco Doni, Disegno partito in piu ragionamenti, ne quali si tratta della scoltura et pintura (Venecia, 1549, p.11).

Garcilaso sin duda debió conocer esa historia si no en todas las versiones sino en todas las versiones al menos alguna de ellas. La profanación que comete el muchacho anónimo con la estatua de Venus podía haber inspirado la imagen de Mario amarrado a la concha de la diosa. Los dos sienten por las respectivas Venus un amor carnal que les impide llevar una vida normal: mientras uno abandona sus quehaceres propios de su condición social, el otro se oculta en el templo para llevar a cabo la profanación.

Para el soneto VII siempre se ha aducido como modelo la oda en que Horacio pide a una antigua amante, Pirra, información sobre su actual compañero, a quien predice, dada su anterior experiencia con la muchacha, una relación tormentosa. Acaba la oda introduciendo el agradecimiento al dios de turno por haberlo librado a él de una travesía marina tan peligrosa. Pero el soneto en cuestión, para algunos aspectos, presenta más analogías con otra oda de Horacio, la III, 26, en que el poeta ha decidido poner fin al amor, al igual que Garcilaso en los dos primeros versos de su soneto. Como símbolo de esa renuncia al amor cuelga en el templo de Venus su lira con que lo cantaba y las armas con que lo combatía. En ese mismo lugar pretende colocar las teas, las palancas y el arco. Como remate y conclusión pide un castigo para la altiva Cloe.

El soneto que siempre se ha considerado la fuente más inmediata de este de Garcilaso es un agradecimiento del poeta a amor por haberlo liberado del naufragio, aunque el toledano tiene en perspectiva uno del que no saldrá indemne. Horacio, en las primeras de las odas citadas, se alegra de haberse salvado del naufragio que podía haberle provocado una dama que está seguro que causará al muchacho al que ha enamorado. En la segunda, pone de manifiesto desde el primer verso su renuncia al amor colgando en las paredes del templo de Cupido los objetos con los que lo celebró y se defendió. Sólo introduce al final la referencia a un castigo para quien se lo ha hecho pasar mal antes de dejarla.

La segunda oda de Horacio tiene en común con la de Garcilaso que expresa desde el primer verso el final del amor y el agradecimiento a su dios por habérselo permitido. El poeta latino asegura «Vixi puellis nuper idoneus/ el militavi non sine gloria» (1-2); enseguida hace alusión a los objetos que deja colgados a modo de exvotos en el templo del dios: «nunc arma defunctumque bello/ barbiton hic paries habebit,/ laevum marinar qui Veneris latus/ custodit» (2-5). En la primera oda de Horacio, recababa datos de una antigua amada de la que se alegra haber podido desenamorarse colgando su ropa mojada en el mismo templo de Amor. Si en aspectos formales, Garcilaso presenta una mayor afinidad con esta segunda oda, en conjunto introduce el mismo planteamiento que la primera al comenzar por la afirmación de haber renunciado al amor y agradecérselo a Cupido de la manera que ya hemos visto. 


\section{Bibliografía}

Antología palatina, Einaudi, Torino, 1978.

Clemente de Alejandría, Protréptico, Gredos, Madrid, 1994.

Horacio, Odas y Epodos, ed. de Manuel Fernández Galiano y Vicente Criatóbal, Cátedra, Madrid, 1990.

Luciano, Amores, en Obras III, Gredos, Madrid, 1990.

Morros Mestres, Bienvenido, "La muerte de Isabel Freyre y el amor napolitano de Garcilaso. Para una cronología de sus églogas y otros poemas», Criticón, 105 (2009), 5-35.

TANsillo, Luigi, I Canzoniere edito ed inedito secondo una copia dell'autografo ed altri manoscritti e stampe, ed. Erasmo Percopo, Napoli Liguori, 1996, 2 vols.

Virgilio, Énéide (livres I-VI), edd. René Durand y André Bellesort, París, Sociéte d'Édition «Les Belles Lettres», 1957, vol. I. 